\title{
First-line Bevacizumab and Paclitaxel for HER2-negative Metastatic Breast Cancer: A French Retrospective Observational Study
}

\author{
VERONIQUE DIERAS ${ }^{1}$, SIMONA POP ${ }^{1}$, FREDERIQUE BERGER ${ }^{2,3}$, MARIE-EGLANTINE DUJARIC $^{2}$, \\ PHILIPPE BEUZEBOC ${ }^{1}$, LAURENCE ESCALUP ${ }^{4}$, FRANÇOIS CLEMENT BIDARD ${ }^{1,3}$, \\ PAUL HENRI COTTU $^{1}$, CHRISTOPHE LE TOURNEAU ${ }^{1}$, SOPHIE PIPERNO-NEUMANN ${ }^{1}$, \\ VALERIE LAURENCE ${ }^{1}$, MATHIEU ROBAIN ${ }^{2}$, BERNARD ASSELAIN ${ }^{2}$ and JEAN-YVES PIERGA ${ }^{1,5}$ \\ ${ }^{1}$ Department of Medical Oncology, ${ }^{2}$ Biostatistics Unit, ${ }^{3}$ INSERM U900, ${ }^{4}$ Pharmacy Department, \\ Curie Institute, PSL Research University, Paris, France; \\ ${ }^{5}$ Descartes University Paris, Paris, France
}

\begin{abstract}
Aim: To assess outcomes in patients treated with first-line bevacizumab-containing therapy for human epidermal growth factor receptor (HER)2-negative metastatic breast cancer $(\mathrm{mBC})$ at a single centre with a homogenous standard-of-care. Patients and Methods: Information on patient and disease characteristics, efficacy, and safety was extracted from computer-based records of all patients receiving first-line bevacizumabpaclitaxel at the Curie Institute, Paris, France, between 2008 and 2011. Results: Median progression-free survival in the 116 treated patients was 13.2 months; median overall survival was 38.4 months. Corresponding values were 9.0 and 18.8 months, respectively, in patients with triple-negative $\mathrm{mBC}$, and 19.4 and 58.8 months, respectively, in patients receiving maintenance endocrine therapy. No new safety signals were seen. Conclusion: Outcomes in patients treated with bevacizumab-paclitaxel at our center were consistent with efficacy in prospective clinical trials, with notable activity in poor-prognosis disease. Maintenance endocrine or oral therapy with bevacizumab after paclitaxel discontinuation was associated with long-term disease control.
\end{abstract}

Bevacizumab is a humanized monoclonal antibody that specifically inhibits vascular endothelial growth factor, a key mediator of angiogenesis. Bevacizumab has

Correspondence to: Véronique Diéras, Institut Curie, 26 rue d'Ulm, 75248 Paris CEDEX, France. Tel: +33 144324675, Fax: +33 153104006, e-mail: veronique.dieras@curie.fr

Key Words: Bevacizumab, metastatic breast cancer, first-line, paclitaxel, HER2-negative. consistently been demonstrated to improve progression-free survival (PFS) and objective response rate when combined with first-line chemotherapy for human epidermal growth factor receptor (HER)2-negative metastatic breast cancer $(\mathrm{mBC})(1-4)$. A pooled analysis of individual patient data from three randomized phase III trials of first-line bevacizumab-containing therapy for HER2-negative $\mathrm{mBC}$ [E2100 evaluating bevacizumab plus paclitaxel (1), AVADO evaluating bevacizumab plus docetaxel (2), and RIBBON-1 evaluating bevacizumab plus a taxane or anthracycline-based combination therapy or capecitabine (3)] demonstrated significantly improved PFS and response rate in patients receiving bevacizumab in combination with chemotherapy versus those treated with chemotherapy alone (5). There was no significant difference in overall survival (OS), although 1-year OS rates were improved with bevacizumab.

The combination of bevacizumab and paclitaxel has demonstrated remarkably consistent efficacy, with median PFS of approximately 11 months in four randomized phase III trials $(1,4,6,7)$. Median OS ranged from 26.5 months in the E2100 (8) and CALGB 40502 (7) trials to 30.5 months in the TURANDOT trial (6). However, in HER2-negative mBC, OS can vary considerably according to biological and clinical factors and subsequent treatments.

Bevacizumab was approved in Europe in combination with first-line paclitaxel for $\mathrm{mBC}$ in 2008 . In France, this therapeutic option is available for all patients receiving firstline chemotherapy for $\mathrm{mBC}$ who have no contraindication for bevacizumab. The purpose of the present retrospective study was to explore the pattern of outcomes in a cohort of patients with $\mathrm{mBC}$ treated with the combination of paclitaxel and bevacizumab at a single institution with a homogeneous standard-of-care reflecting general oncology practice. 


\section{Patients and Methods}

In this retrospective study conducted at the Curie Institute, Paris, France and approved by the Institutional Review Committee, computer-based records of chemotherapy prescriptions were screened to identify all women who had received bevacizumab combined with paclitaxel as first-line therapy for HER2-negative mBC between February 2008 and April 2011. In accordance with the approved indication, bevacizumab was continued until disease progression or unacceptable toxicity.

Information was extracted from the records on patient demographics, disease characteristics, previous treatment, medical history, duration of bevacizumab therapy, maintenance oral or endocrine therapy, grade 3/4 adverse events, reason for treatment discontinuation, and death. Analyses of safety, PFS, and OS were planned. Additional exploratory subgroup analyses of efficacy according to key clinical characteristics were pre-specified, including hormone receptor status (triple negative $v s$. hormone receptor positive), visceral disease (yes $v s$. no), and number of metastatic sites $(<3 v s . \geq 3$ ).

Descriptive methods, including median and ranges, were used to summarize quantitative baseline characteristics of patients. OS and PFS were defined as the time from the start of first-line therapy with bevacizumab-paclitaxel until death (OS) or the date of first progression or death, whichever occurred earlier (PFS). Patients lost to follow-up were censored at their last follow-up visit. PFS and OS were estimated using the Kaplan-Meier method and compared using $\log$-rank tests. A $p$-value of less than 0.05 was considered to be statistically significant. All analyses were performed using R software (version 2.13.2) (http://cran.r-project.org).

\section{Results}

The analysis population comprised of 116 patients treated with bevacizumab-paclitaxel (Table I). The median duration of follow-up from the start of bevacizumab-paclitaxel to the time of data cut-off was 47 months (range=5.9-61.4 months). At this time, 106 patients $(91 \%)$ had experienced a PFS event and $65(56 \%)$ had died. Median PFS in the overall population was 13.2 months [95\% confidence interval $(\mathrm{CI})=10.8-17.0$ months] and median OS was 38.4 months (95\% CI=31.3-52.3 months). Figure 1 shows efficacy in pre-specified subgroups defined by important clinical characteristics. All three of the explored characteristics were significant prognostic factors for PFS; triple-negative status was also a significant prognostic factor for OS, but presence of visceral metastases and number of metastatic organ sites were not, although interpretation is limited by the very small sample sizes of some subgroups.

The median duration of treatment exposure was 8.5 months (range=1-43.5 months) for bevacizumab and 5.1 months (range $=1-12$ months) for paclitaxel. In the majority of cases (96 patients; $83 \%$ ), paclitaxel was discontinued before evidence of disease progression, most commonly because of maximal response or adverse events, particularly neuropathy. Of these 96 patients, $79(82 \%)$ received maintenance therapy combined with bevacizumab: 60 (63\%) received maintenance endocrine therapy and 24 (25\%) received oral chemotherapy (capecitabine
Table I. Baseline characteristics.

\begin{tabular}{lc}
\hline Characteristic & Value (n=116) \\
\hline Median age, years (range) & $53(28-84)$ \\
ECOG performance status, $\mathrm{n}(\%)$ & \\
0 & $70(60)$ \\
1 & $40(34)$ \\
2 & $6(5)$ \\
Hormone receptor status, $\mathrm{n}(\%)^{\mathrm{a}}$ & \\
Estrogen and/or progesterone positive & $97(84)$ \\
Triple-negative & $15(13)$ \\
De novo metastatic breast cancer, $\mathrm{n}(\%)$ & $17(15)$ \\
Median disease-free interval, months (range) & $47(0-220)$ \\
$\geq 3$ involved organ sites, $\mathrm{n}(\%)$ & $38(33)$ \\
Metastatic organ sites, $\mathrm{n}(\%)$ & $73(63)$ \\
Bone & $28(24)$ \\
Lung & $55(47)$ \\
Liver & $20(17)$ \\
Soft tissue & $3(3)$ \\
Central nervous system & $99(85)$ \\
Prior neo(adjuvant) chemotherapy, $\mathrm{n}(\%)$ & $54(47)$ \\
Anthracycline and/or taxane & $45(39)$ \\
Other & \\
Prior endocrine therapy, n $(\%)$ & $71(61)$ \\
Early breast cancer & $16(14)$ \\
Metastatic breast cancer & \\
\hline
\end{tabular}

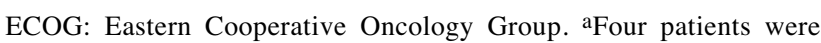
neither estrogen and/or progesterone receptor-positive, nor triplenegative because of missing HER2 status.

or cyclophosphamide). Exploratory analyses according to the maintenance treatment strategy after discontinuation of paclitaxel suggested the longest PFS and OS in patients who received endocrine therapy with bevacizumab, and the shortest in those who received no maintenance therapy (Table II).

The safety profile was as expected with this combination. Grade 3 or more adverse events were recorded in $46 \%$ of patients. The most common were hypertension $(17 \%)$, arterial/venous thromboembolism (12\%), bleeding (6\%), and proteinuria $(6 \%)$. Wound-healing complications were reported in four patients $(3 \%)$, osteonecrosis of the jaw in three patients (3\%), and gastrointestinal perforation in one patient (1\%). Two patients died while receiving therapy: one on day 17 of cycle 1 from vomiting and abdominal pain, and one during cycle 3 from cerebral thromboembolism. In both patients, these adverse events were associated with disease progression in the liver. Bevacizumab was discontinued because of adverse events (mainly hypertension) in 41 patients (35\%).

\section{Discussion}

Our experience of first-line bevacizumab-paclitaxel therapy in routine clinical practice reflects outcomes in prospective clinical trials. The median PFS of 13.2 months is at least as 
A

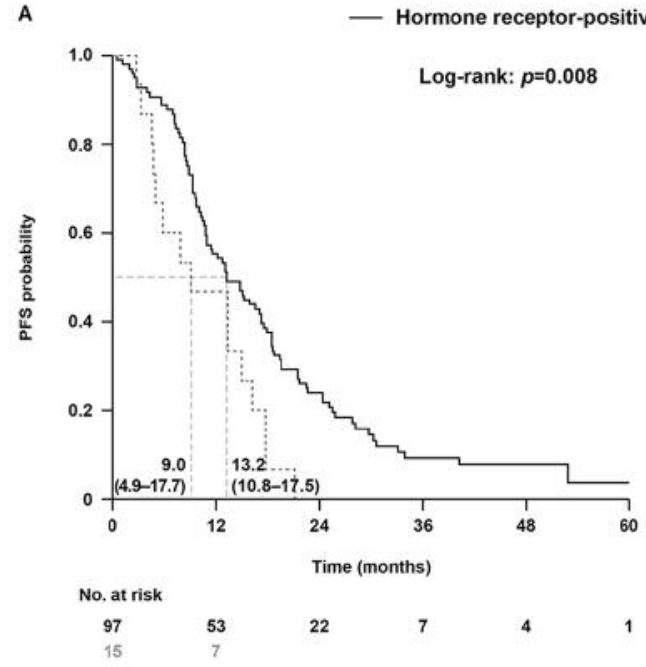

B

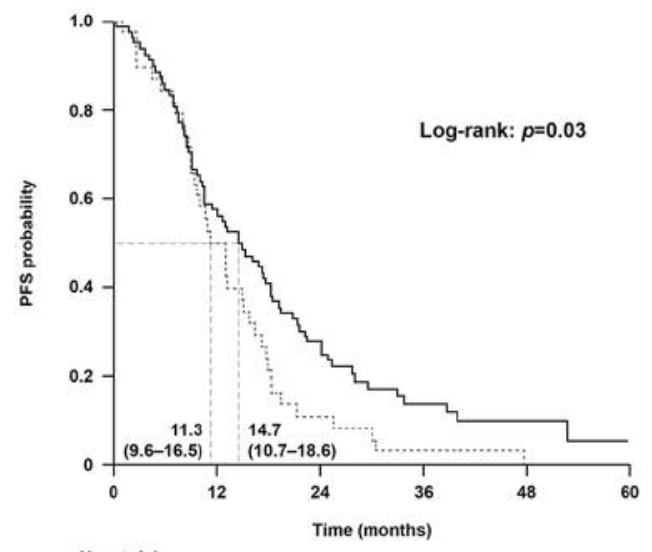

No. at risk

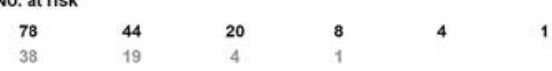

...... Triple-negative $(n=15)$

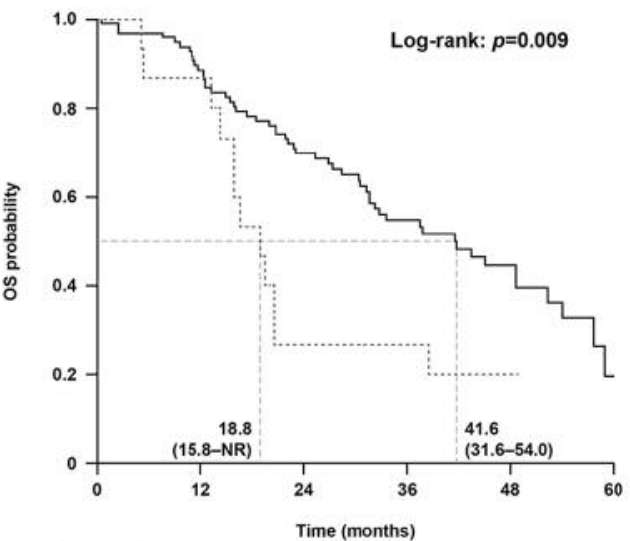

No. at risk

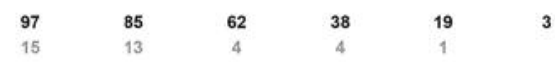

..... $\geq 3$ metastatic sites $(n=38)$

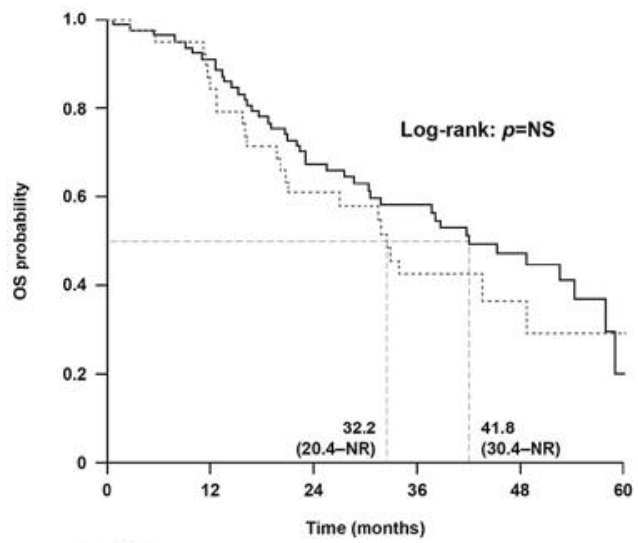

No. at risk

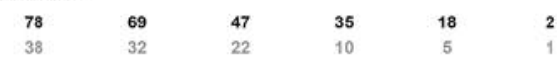

C

- No visceral metastases $(n=35) \quad \ldots$. Visceral metastases $(n=81)$
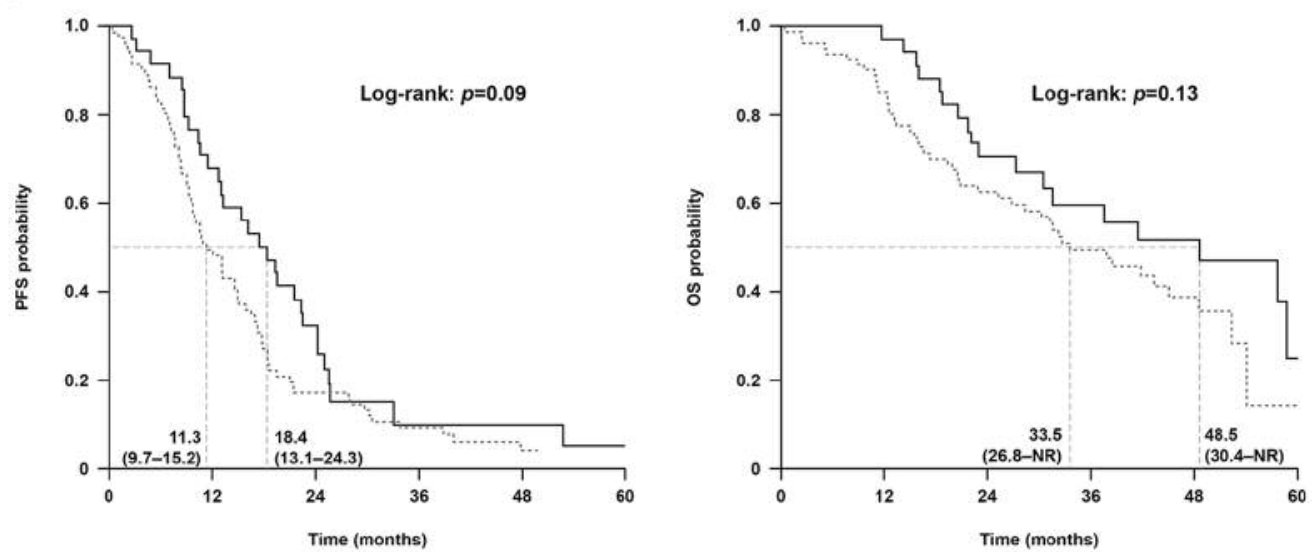

No. at risk
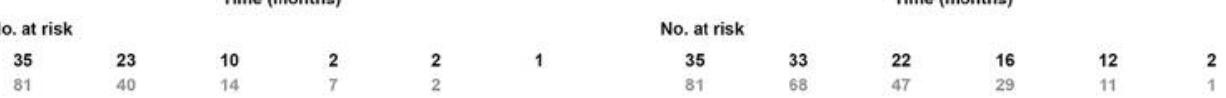

Figure 1. Subgroup analyses of progression-free survival (PFS) and overall survival (OS) according to clinical characteristics. A: Hormone receptorpositive versus triple-negative. $B:<3$ versus $\geq 3$ metastatic sites. $C:$ No visceral versus visceral metastases. Vertical dotted lines represent median (95\% confidence interval) values. NR: Not reached. 
Table II. Efficacy according to maintenance therapy.

\begin{tabular}{lcc}
\hline Maintenance therapy after stopping paclitaxel & Median PFS (95\% CI), months & Median OS (95\% CI), months \\
\hline All patients $(\mathrm{n}=116)$ & $13.2(10.8-17.0)$ & $38.4(31.3-52.3)$ \\
None $(\mathrm{n}=17)^{\mathrm{a}}$ & $12.1(8.4-14.9)$ & $22.9(16.5-\mathrm{NR})$ \\
Endocrine therapy $(\mathrm{n}=60)^{\mathrm{b}}$ & $19.4(17.2-25.5)$ & $58.8(48.5-\mathrm{NR})$ \\
Oral chemotherapy $(\mathrm{n}=24)^{\mathrm{c}}$ & $17.2(11.3-21.6)$ & $37.5(20.6-\mathrm{NR})$ \\
\hline
\end{tabular}

CI: Confidence interval, NR: not reached, OS: overall survival, PFS: progression-free survival. aPatients who discontinued paclitaxel before disease progression but received no maintenance therapy. batients who discontinued paclitaxel before disease progression and received maintenance

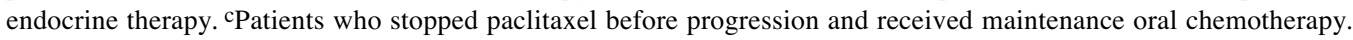

long as that reported in four randomized phase III trials evaluating bevacizumab-paclitaxel $(1,4,6,7)$ and in the subgroup of patients receiving weekly paclitaxel and bevacizumab in the large multinational ATHENA study (9). The median OS of 38.4 months is longer than that reported in the phase III trials (6-8). Encouraging activity was observed in specific populations with a poor prognosis, such as triplenegative $\mathrm{mBC}$ : median PFS of 9.0 months in this population is within the range reported in subgroups with triple-negative disease in the trials mentioned above. Triple-negative disease was prognostic for worse OS in bevacizumab-treated patients.

In routine practice, maintenance endocrine therapy with (or without) bevacizumab is frequently offered to patients; however, there is little information on the value of this approach. In the RIBBON-1, TURANDOT, and ATHENA trials $(3,6,9)$, maintenance endocrine therapy given concurrently with bevacizumab was not permitted. Small retrospective analyses provide limited data supporting such a strategy $(10,11)$, and results of the prematurely terminated randomized phase III AROBASE trial suggest similar efficacy with maintenance bevacizumab plus exemestane versus continued bevacizumab plus taxane following initial bevacizumab plus taxane therapy (12). In the cohort of patients described in this paper, PFS and OS were longer in patients receiving endocrine maintenance therapy and, to a lesser extent, maintenance oral chemotherapy with bevacizumab compared with patients who received no maintenance therapy. These exploratory analyses should be interpreted with great caution. The decision concerning whether to give maintenance therapy is likely to have been influenced by the condition of the patient, which introduces bias, and this subgroup might represent a population with a better prognosis able to continue first-line therapy for a prolonged period. Nevertheless, it is interesting to note the sustained disease control in patients receiving maintenance endocrine therapy with bevacizumab after bevacizumab-paclitaxel (median PFS 19.4 months).

In contrast to maintenance endocrine therapy, there is evidence from the randomized phase III IMELDA trial supporting the use of maintenance capecitabine with bevacizumab after initial bevacizumab-taxane therapy (13).
The addition of capecitabine to bevacizumab maintenance therapy was shown to significantly improve both PFS (primary end-point; hazard ratio $=0.38$ ) and OS (secondary end-point; hazard ratio $=0.43$ ) compared with single-agent bevacizumab maintenance therapy.

Collection of safety data in this study was limited by the retrospective design. However, there were no new safety signals and, consistent with the well-characterized safety profile of bevacizumab-containing therapy in $\mathrm{mBC}$, the most frequently reported adverse effects were hypertension, thromboembolic events, proteinuria, and bleeding.

Our study reflects outcomes in a large cohort of patients treated in routine oncology practice at a single institution with a homogeneous standard of care. Such studies provide important understanding of the risks and benefits of evolving treatment strategies in real-world practice, and provide insights into the relevance and applicability of outcomes demonstrated in prospective clinical trials and their broader use in the context of everyday clinical practice. Outcomes in this cohort support the use of bevacizumab as indicated in France. The efficacy and tolerability consistently demonstrated in phase III trials were replicated in our cohort of patients treated with bevacizumab in routine oncology practice at the Curie Institute, with notable activity in patients with a poor prognosis. Ongoing research activity in France includes a collaboration with UNICANCER to prospectively evaluate potential predictive biomarkers for bevacizumab activity in the ongoing COMET study (ClinicalTrials.gov Identifier NCT01745757).

\section{Acknowledgements}

This study was supported by Roche France. Third-party medical writing support was provided by Jennifer Kelly.

\section{References}

1 Miller K, Wang M, Gralow J, Dickler M, Cobleigh M, Perez EA, Shenkier T, Cella D and Davidson NE: Paclitaxel plus bevacizumab versus paclitaxel alone for metastatic breast cancer. N Engl J Med 357: 2666-2676, 2007. 
2 Miles DW, Chan A, Dirix LY, Cortés J, Pivot X, Tomczak P, Delozier T, Sohn JH, Provencher L, Puglisi F, Harbeck N, Steger GG, Schneeweiss A, Wardley AM, Chlistalla A and Romieu G: Phase III study of bevacizumab plus docetaxel compared with placebo plus docetaxel for the first-line treatment of human epidermal growth factor receptor 2-negative metastatic breast cancer. J Clin Oncol 28: 3239-3247, 2010.

3 Robert NJ, Diéras V, Glaspy J, Brufsky AM, Bondarenko I, Lipatov ON, Perez EA, Yardley DA, Chan SY, Zhou X, Phan SC and O'Shaughnessy J: RIBBON-1: randomized, double-blind, placebo-controlled, phase III trial of chemotherapy with or without bevacizumab for first-line treatment of human epidermal growth factor receptor 2-negative locally recurrent or metastatic breast cancer. J Clin Oncol 29: 1252-1260, 2011.

4 Miles D, Cameron D, Bondarenko I, Manzyuk L, Carlos Alcedo J, Lopez RI, Im S-A, Canon J-L, Shparyk Y, Yardley DA, Masuda N, Ro J, Denduluri N, Hubeaux S, Quah C, Bais C and O'Shaughnessy J: Bevacizumab plus paclitaxel versus placebo plus paclitaxel as first-line therapy for HER2-negative metastatic breast cancer (MERiDiAN): A double-blind placebo-controlled randomised phase III trial with prospective biomarker evaluation. Eur J Cancer 70: 146-155, 2017.

5 Miles DW, Diéras V, Cortés J, Duenne AA, Yi J and O'Shaughnessy J: First-line bevacizumab in combination with chemotherapy for HER2-negative metastatic breast cancer: pooled and subgroup analyses of data from 2447 patients. Ann Oncol 24: 2773-2780, 2013.

6 Zielinski C, Láng I, Inbar M, Kahán Z, Greil R, Beslija S, Stemmer SM, Zvirbule Z, Steger GG, Melichar B, Pienkowski T, Sirbu D, Petruzelka L, Eniu A, Nisenbaum B, Dank M, Anghel R, Messinger D and Brodowicz T; TURANDOT investigators: Bevacizumab plus paclitaxel versus bevacizumab plus capecitabine as first-line treatment for HER2-negative metastatic breast cancer (TURANDOT): primary endpoint results of a randomised, open-label, non-inferiority, phase 3 trial. Lancet Oncol 17: 1230-1239, 2016.

7 Rugo HS, Barry WT, Moreno-Aspitia A, Lyss AP, Cirrincione C, Mayer EL, Naughton M, Layman RM, Carey LA, Somer RA, Perez EA, Hudis C and Winer EP: Randomized phase III trial of paclitaxel once per week compared with nanoparticle albuminbound nab-paclitaxel once per week or ixabepilone with bevacizumab as first-line chemotherapy for locally recurrent or metastatic breast cancer: CALGB 40502/NCCTG N063H (Alliance). J Clin Oncol 33: 2361-2369, 2015.
8 Cameron D: Bevacizumab in the first-line treatment of metastatic breast cancer. Eur J Cancer Suppl 6: 21-28, 2008.

9 Smith I, Pierga JY, Biganzoli L, Cortes-Funes H, Thomssen C, Saracchini S, Nisenbaum B, Pelaez I, Duenne AA and Pritchard KI: Final overall survival results and effect of prolonged $(\geq 1$ year) first-line bevacizumab-containing therapy for metastatic breast cancer in the ATHENA trial. Breast Cancer Res Treat 130: 133-143, 2011.

10 Fabi A, Russillo M, Ferretti G, Metro G, Nisticò C, Papaldo P, De Vita F, D'Auria G, Vidiri A, Giannarelli D and Cognetti F: Maintenance bevacizumab beyond first-line paclitaxel plus bevacizumab in patients with HER2-negative hormone receptorpositive metastatic breast cancer: efficacy in combination with hormonal therapy. BMC Cancer 12: 482, 2012.

11 Redondo A, Martínez V, Zamora P, Castelo B, Pinto A, Cruz P, Higuera $\mathrm{O}$, Mendiola $\mathrm{M}$, Hardisson $\mathrm{D}$ and Espinosa $\mathrm{E}$ : Continuation of bevacizumab and addition of hormone therapy following weekly paclitaxel therapy in HER2-negative metastatic breast cancer. Onco Targets Ther 7: 2175-2181, 2014.

12 Trédan O, Follana P, Moullet I, Cropet C, Trager-Maury S, Dauba J, Lavau-Denes S, Diéras V, Béal-Ardisson D, Gouttebel M, Orfeuvre H, Stefani L, Jouannaud C, Bürki F, Petit T, Guardiola E, Becuwe C, Blot E, Pujade-Lauraine E and Bachelot T: A phase III trial of exemestane plus bevacizumab maintenance therapy in patients with metastatic breast cancer after first-line taxane and bevacizumab: a GINECO group study. Ann Oncol 27: 1020-1029, 2016.

13 Gligorov J, Doval D, Bines J, Alba E, Cortes P, Pierga JY, Gupta V, Costa R, Srock S, de Ducla S, Freudensprung U and Mustacchi G: Maintenance capecitabine and bevacizumab versus bevacizumab alone after initial first-line bevacizumab and docetaxel for patients with HER2-negative metastatic breast cancer (IMELDA): a randomised, open-label, phase 3 trial. Lancet Oncol 15: 1351-1360, 2014.

Received October 28, 2016

Revised February 2, 2017

Accepted February 7, 2017 